\title{
An Analysis of the Physical Activity of Special Olympic Athletes with the Use of an Accelerometer
}

\author{
Hana Válková ${ }^{1}, \mathrm{Lu} \mathrm{Qu}^{2,3}$ and Frantisek Chmelík ${ }^{3}$ \\ 1. Faculty of Sport Studies, Masaryk University, Brno 602 00, Czech Republic \\ 2. Faculty of Physical Education and Physiotherapy, Leuven B-3001, Belgium \\ 3. Faculty of Physical Culture, Palacký University, Olomouc 77111, Czech Republic
}

\begin{abstract}
Background: Studies indicate that people with a mental disability are less engaged in physical activity than their peers. The published data was mainly collected from oral feedback and the measurements taken from the use of pedometers. People with a mental disability engage in different types of physical activity, not only walking. The intention of this study was to assess physical activity using an accelerometer during a Special Olympics competition. Objective: To measure the physical activity of athletes with a mental disability during the Special Olympics national program using an accelerometer and to analyze the level of physical activity in relation to different disciplines, and in accordance with the gender of the participants. Methods: 75 athletes with a mental disability (50 males and 25 females) wore a GT3X ActiGraph to record their physical activity levels for two days during the Athletics Games in Olomouc, Czech Republic. Results: (1) The physical activity levels of the athletes met the published guidelines; (2) athletes who participated in both track and field events do not have higher energy expenditure than those participating only in field events; (3) athletes with a greater sporting ability are more physically active; (4) male athletes do not have a higher physical activity level. Conclusion: Regarding the level of physical activity, the local Special Olympic program is beneficial for people with a mental disability.
\end{abstract}

Key words: Mental disability, physical activity, energy expenditure, steps, accelerometer.

\section{Introduction}

Engagement in PA (physical activity) is a healthy behavior that has a positive impact on body composition, skeletal health and several aspects of psychological health, including self-concept and self-esteem. These health benefits include decreased mortality rates, lower incidence of developing diseases, enhancement in conditions such as hypertension, diabetes and obesity, improvement in mood and well-being, and the lessening of functional decline [1].

International government agencies and research groups have published guidelines on the amount of PA people should participate in. They state that people should participate in at least 30 minutes of moderate

Corresponding author: Hana Válková, Ph.D., professor, research fields: sport psychology and adapted physical activity. E-mail: valkova@fsps.muni.cz. intensity PA each day [2, 3]. In addition, it is recommended that we perform 20 minutes of continuous vigorous activity at least three days a week to improve cardiovascular health [4]. The PA behavior of adults with a mental disability, consistent with the U.S. Surgeon General's recommendation, is 30 minutes of moderate intensity PA five or more days per week. More specifically, moderate activity includes large muscle group activities, which is equivalent to brisk walking, dancing and yard work; with vigorous activity including repetitive large muscle activity at an intensity equal to $70 \%$ of the age-predicted maximum heart rate (e.g., jogging and lap swimming).

There are findings which suggest that people with disabilities are less active than the general population [5]. Related to a categorical approach [6], the presented research is oriented towards adults with a 
mental disability. The term "mental disability" is used, despite the use of the term "intellectual disability" in the English language or "mental retardation" used by the Special Olympics organization up to 2008 [7]. The reason is relevant to the definition by the World Health Organization [3] which states that "mental disability refers to substantial limitations in present functioning. It is characterized by significantly sub-average intellectual functioning, existing concurrently with related limitations in two or more applicable adaptive skill areas: communication, self-care, home-living, social skills, community use, self-direction, health and safety, functional academics, leisure and work. Mental disability manifests itself before age 15." The definition suggests that disability is not only apparent in the cognitive and intellectual domain, but transcends a person's whole personality [8]. The PA inactivity issue has been studied since the 1970s [6], e.g., Cratty [9] and Kephart [6]. The main idea presented was: "movement is the basis for intellectual development." He discussed a lot of motor features relevant to the maturation of the CNS (central nervous system) or "brain maturation", such as motor exploration, reflex and postural adjustment, balance, laterality and directionality and body image. He began to compose perceptual motor development programs to test and evaluate general child development and/or children with developmental delay [6]. The issues of mental disability, PA and other associated problems like congenital heart defects, muscle hypo-tonicity, joint hypermobility, low cardiovascular fitness and decreased muscle strength are well documented [10-14]. Taking this into consideration, participation in regular PA by people with a mental disability is essential for their health; however this is not the reality. Physical inactivity of persons with a mental disability in relation to fitness, risk to health and obesity was examined by Fernhall et al. [15], Onywadume [16], Robertson et al. [17] and Yamaki [18].

Studies indicate that people with a mental disability are less engaged in PA, more sedentary and less likely to be physically fit than their peers [19-24]. It is reported that $56 \%$ of people with disabilities do not engage in any leisure time activity, compared to $36 \%$ of people without disabilities [2]. Less than $20 \%$ of adults with disabilities engage in vigorous activities that promote fitness or muscular strength [2]. Stanish et al. [25] found that the major sources of PA for adults with a mental disability were walking and cycling, chores and work, dancing and the Special Olympics. Walking was by far the most prevalent form of PA, but studies suggest the intensity may not be sufficient to meet the minimum recommendations to achieve health benefits [23, 25]. Findings from research carried out on Czech Special Olympians documented that both adolescent males and females spent approximately $7.5 \%$ or 53 minutes of their day partaking in moderate physical activity [8].

Meanwhile, in a pilot study by Shields et al. [26], almost $58 \%$ of children with a mental disability, particularly with Down syndrome, did not perform the recommended amount of PA to maintain good health, and none performed the recommended level of continuous vigorous PA to enhance cardiovascular fitness. A significant inverse association was found between the amount of activity undertaken and age, with older children taking part in less activity. Nevertheless, people with a mental disability have a lower $\mathrm{VO}_{2}$ peak than those without a disability; therefore the levels for moderate and vigorous activity of the average person may not be appropriate for the mentally disabled [17].

Pitteti et al. [27] assessed the fitness of adult Special Olympic participants. In 2010, they compared the advantages and disadvantages between using a classic pedometer and an accelerometer in children aged 6-10 [28]. A pedometer is used for taking measurements when walking, whereas an accelerometer is used for other activities besides walking. Children with a mental disability engage in different types of PA, not only walking. Until recently, 
there have been no studies that validate the use of an accelerometer for people with a mental disability during an exercise program intervention. Therefore, it is necessary to find out if a well-planned exercise program, like the Special Olympic Local/National Program, can help to enhance the fitness of people with a mental disability, and help them establish a good daily routine of the recommended amount of PA. In the meantime, it can assist health professionals involved in disease prevention to develop strategies that will enhance the participation in physical activities of people with a mental disability.

\section{The Objective of the Study}

The objective of this study is to measure PA using an accelerometer in athletes with a moderate level of mental disability during a SONAC (Special Olympics National Athletic Competition), and to analyze the level of PA in relation to different disciplines (events) and the gender of participants. This will be done with the intention to provide detailed information that can be used for optimizing the PA routine of people with a mental disability. In order to meet the objective, the PA levels of Special Olympic athletes taking part in a local program were measured over two days: (1) to determine if they satisfied published guidelines on PA levels; (2) to determine the differences in PA levels between genders, between different types of activities and between the different intensities of the events, by comparing energy expenditure, intensity and the duration of PA.

\section{Methods}

\subsection{Participants}

Participants were recruited for the SONAC in the city of Olomouc, Czech Republic, in August 2009 (Table 1). Ninety-seven Special Olympic athletes with a moderate mental disability (IQ scale points approx. 40-70) were invited to participate in this study during the four day competition, by wearing an accelerometer to record their PA levels. Only two days of athletic competition (1st day preliminary, 2nd day final) were analyzed. Athletes were aged from 13 to 48 years and all of the experienced Special Olympians have a minimal three years training. One third of them were female (25) and two thirds were male (50).

Seventy-five athletes' data was useable, mainly for two reasons: (1) some athletes would not tolerate wearing an accelerometer, so the data was incomplete; (2) some participants' record sheets were not completed properly, and therefore it was not possible to process the data from the accelerometers; (3) the cerebral palsy athletes (seven participants) used the accelerometer (they liked it), but their results have not been processed due to their motor problems.

\subsection{Equipment}

Objective monitoring of PA, using body worn accelerometers and pedometers, has advanced greatly in recent years. In this study, the researcher used an accelerometer ActiGraph GT3X [29].

PA can be quantified in a variety of ways. It is often categorized by type, intensity, frequency and duration, as well as by the environmental and social conditions under which it takes place [30]. Consequently, PA may be expressed in terms of energy expenditure (Kcal, Kcal $/ \mathrm{kg} / \mathrm{hr}$, or METs (metabolic equivalent of energy)), or alternatively in terms of the time period of activity (hours or minutes) or in units of movement (counts or steps).

Table 1 Description of participants (Mean \pm SD).

\begin{tabular}{llll}
\hline & Sample $(N=75)$ & Males $(N=50)$ & Females $(N=25)$ \\
\hline Age (years) & $29.2 \pm 10.7$ & $31.9 \pm 9.9$ & $23.8 \pm 10.3$ \\
Weight $(\mathrm{kg})$ & $69.2 \pm 15.2$ & $72.8 \pm 12.7$ & $62.0 \pm 17.5$ \\
Height $(\mathrm{cm})$ & $168.6 \pm 10.6$ & $172.9 \pm 9.1$ & $159.9 \pm 7.9$ \\
BMI (body mass index) $\left(\mathrm{kg} / \mathrm{m}^{2}\right)$ & $24.2 \pm 4.3$ & $24.3 \pm 3.6$ & $24.1 \pm 5.7$ \\
\hline
\end{tabular}


The ActiGraph's new GT3X activity monitor uses a solid state triaxial accelerometer to collect motion data on three axes for the highest level of analytic capabilities available. The GT3X is lightweight and compact, weighing 27 grams and measuring $3.8 \mathrm{~cm} \times$ $3.7 \mathrm{~cm} \times 1.8 \mathrm{~cm}$. The ActiGraph GT3X worn on the waist provides PA measurements such as activity counts, step counts, energy expenditure, activity levels, etc. The ActiGraph can also be worn on the wrist to provide general activity monitoring for the elderly or wheel-chair bound individuals.

\subsection{Placement of Monitor}

During the monitoring, the participants wore the accelerometer (GT3X) on their right hip. Athletes and their coaches were informed about how to wear and handle the monitor (water protection, sleeping time, etc.). They understood and liked it and were proud to use it.

\subsection{Program Design (Special Olympic Local Program Schedule)}

The Athletics Games in Olomouc were held on Aug. 23rd to 26th 2009 as the SONAC, when the flora festival (flower exhibition) was opened in the city of
Olomouc. The games were held over four days. On the first afternoon (Aug. 23rd), the Healthy Athletes program, including the application of the accelerometer was organized. The athletes had the chance to go for a walk and visit the flower exhibition. On the second day (Aug. 24th), only preliminary competitions took place, and on the third day (Aug. 25 th), only final competitions and medal ceremonies took place. The event culminated with a disco-party. The schedule for two days of activity is exactly the same, which means that the Special Olympic athletes took part in the same games at the same time during these 2 days. The games started at 9:00 in the morning and finished at about 14:45 in the afternoon. Table 2 shows the athletics games events in Olomouc.

According to Special Olympics Athletics rules [31], the athletic events are divided into high-level and low-level events. The regulation reflects athletes' ability and their safety. Athletes can compete either in a combination of high-level (2 events plus relay) or low-level ( 2 events) events. The high-level events and the low-level events are shown in Table 3 below.

\subsection{Data Collection}

The ActiGraph GT3X monitor was assigned to every

Table 2 The events of the Special Olympics National Athletic Competition.

\begin{tabular}{llll}
\hline Track events & Race walking events & Field events & Combined events \\
\hline 50 meters & 50 meters walk & Standing long jump & Tetrathlon (100 meters, long jump, shot put, 400 meters) \\
100 meters & 100 meters walk & Long jump & $4 \times 100$ meters relay \\
200 meters & & Softball throw $150 \mathrm{~g}$ & \\
& & Shot put & \\
400 meters & & a. men: $4.0 \mathrm{~kg}$ & \\
& & b. women: $3.0 \mathrm{~kg}$ & \\
800 meters & & \\
1,500 meters & & & \\
\hline
\end{tabular}

Table 3 The high-level athletic events and low-level athletic events.

\begin{tabular}{lll}
\hline High-level events track & High-level events field & Low-level events track and field \\
\hline 100 meters & Long jump & 50 meters run \\
200 meters & Shot put & 50 meters walk \\
400 meters & Tetrathlon & 100 meters walk \\
800 meters & & Standing long jump \\
1,500 meters & & Softball throw $150 \mathrm{~g}$ \\
$4 \times 100$ meters relay & & \\
\hline
\end{tabular}


participant to record their daily PA level when they registered for the competition (the first afternoon). Data was recorded during the two days of the athletics competition, both during the competition and in the athletes' daily activity out of competition, including the disco-party on the final evening. The ActiGraph GT3X monitors were worn when the athletes got up in the morning until they went to bed at night. Coaches were informed how to handle this equipment and how to wear and care for it. After the SONAC, the ActiGraph GT3X monitors were collected from the coaches and the data was downloaded using a USB 2.0 connection to a computer, using ActiLife 4.1 software.

As the accelerometer assessment was included in the SO Healthy Athlete Program (supported by the Europe/Eurasia SO HA Board), parents and/or caregivers were informed and signed consent letters to allow participation in the healthy athlete assessment.

\subsection{Statistical Analysis}

Statistical analysis was performed using Statistica 9.0. Significance for statistical analysis was set at the 0.05 alpha level. To estimate the effect size, coefficient $d$ was calculated.
Descriptive statistics were calculated for all variables from the ActiGraph. The duration of PA is calculated in hours, while the intensity of PA is recorded in steps/days and METs. The energy expenditure is calculated in $\mathrm{kcal} / \mathrm{kg} / \mathrm{hr}$. The Mann-Whitney U-test was conducted to test the differences between the studied variables.

\section{Results}

\subsection{The Overall PA Levels during the SONAC}

Both the PA time and PI (physical inactivity) time was recorded in hours during the 2-day local event. Fig. 1 shows that the active time of the athletes during these two days accounts for around $60 \%$ of the total measured time, which means that the athletes are relatively active during the Special Olympics.

More specifically, the time the athletes spend taking part in PA of different intensities is demonstrated in Fig. 2. The time the athletes spend taking part in moderate-vigorous PA is over 60 minutes per day.

Meanwhile, the amount of steps was also measured (Fig. 3). The average number of the steps by both female and male athletes exceeds 10,000 steps per day, which is the recommended guideline.

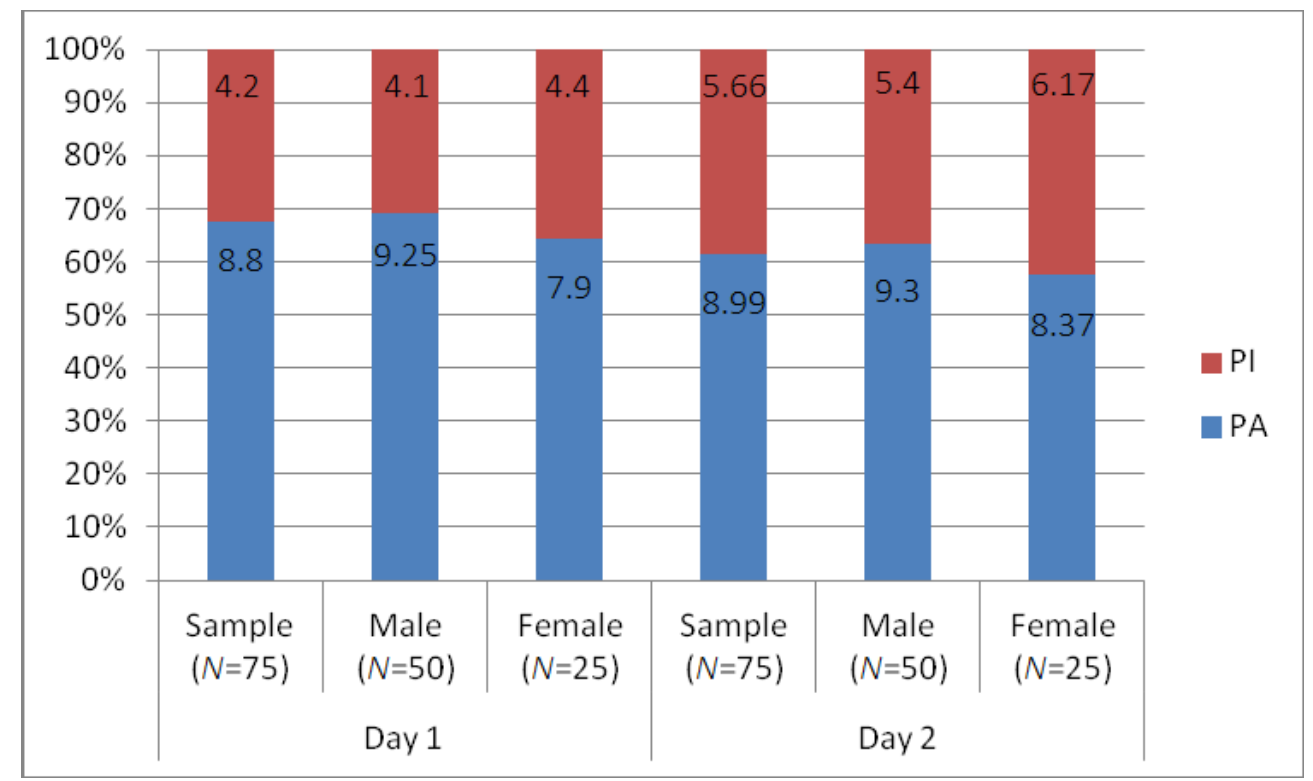

Fig. 1 The overall active and inactive hours of the Special Olympic athletes during the SONAC.

PI: physical inactivity; PA: physical activity. 


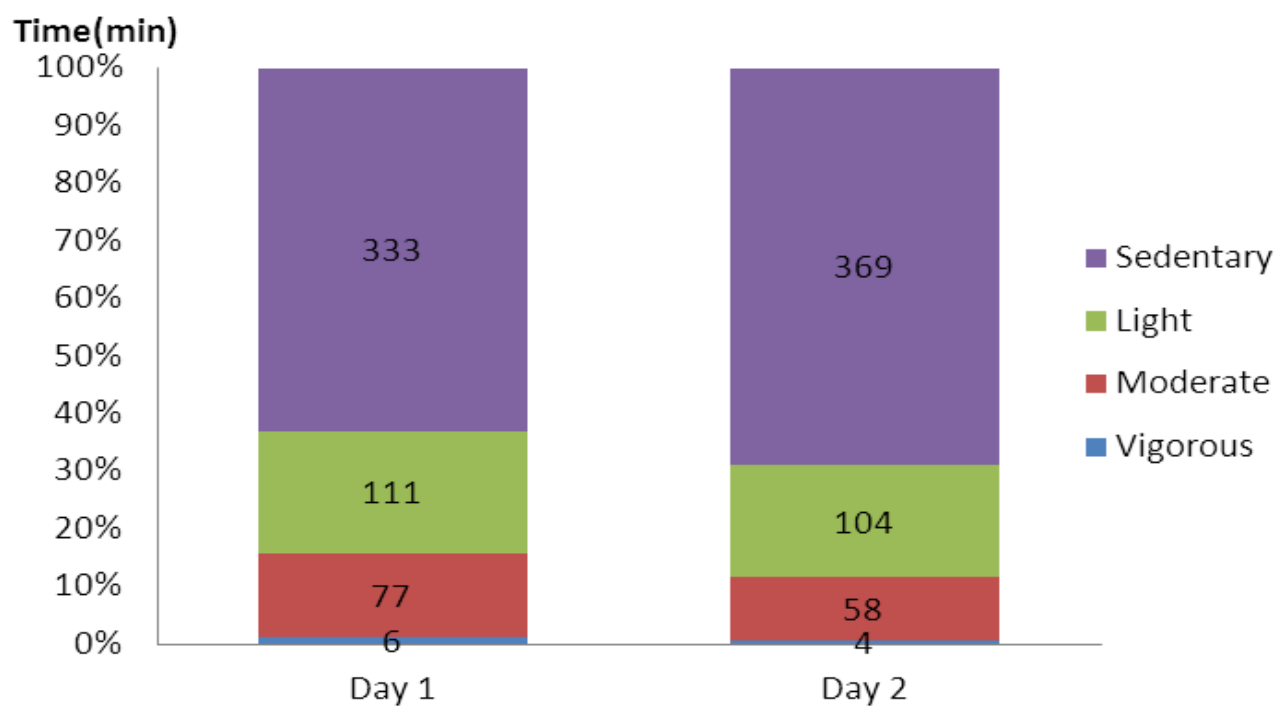

Fig. 2 The time the athletes spent taking part in different PA levels during the SONAC.

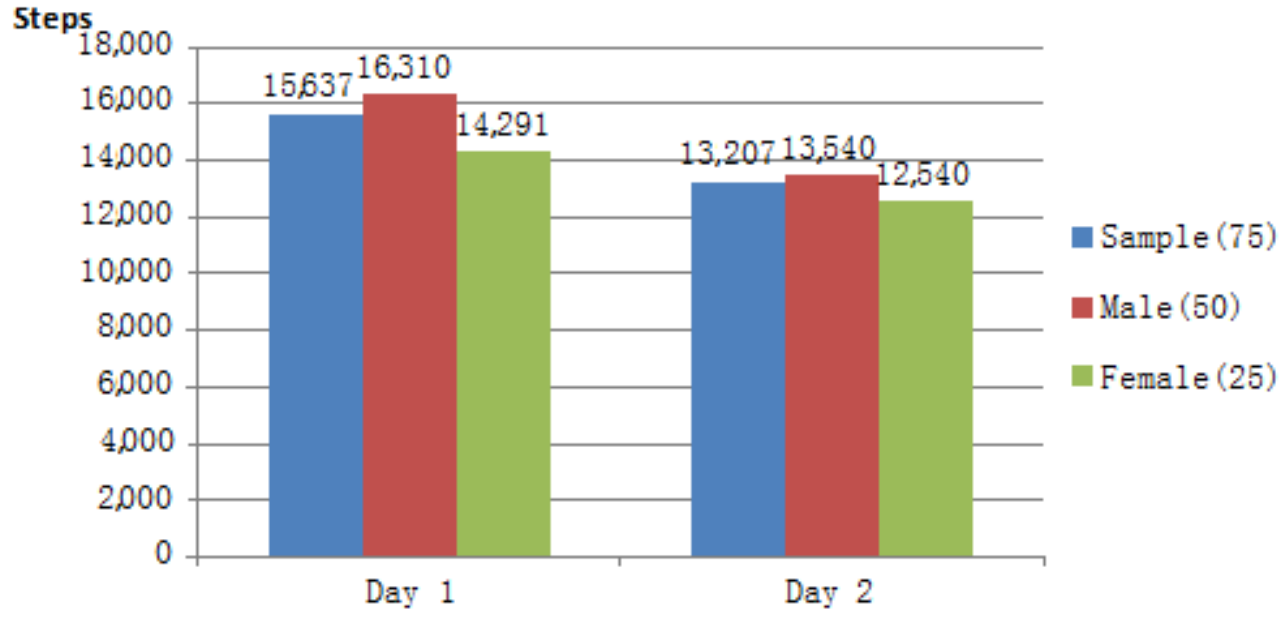

Fig. 3 Average steps taken by athletes during the SONAC.

\subsection{The Comparison of Energy Expenditures for Different Types of PA}

Most athletes took part in two events during the SONAC; the PA of the athletes who participated in both track and field events and those who only participated in track events were compared using four variables:

(1) relative active energy expenditure per hour (RAEE/h), (kcal/kg/hr);

(2) total relative energy expenditure per hour for the time of measurement (RTEE/h), (kcal/kg/hr);

(3) total relative energy expenditure per hour per 24 hours (TREE/h/24), (kcal/kg/hr);

(4) number of steps (number).
As shown in Table 4, it was found that in the preliminary games only female athletes who participated in both track and field events have higher energy expenditures than those who participated in only track events in terms of RAEE/h, RTEE/h, TREE/h/24 and steps. However, it is interesting to note that in the final events (the second day), the track athletes took more steps than the track and field athletes, and a significant difference is shown especially in male athletes (Table 5).

No significant differences were found in active energy expenditure between athletes participating in track and field events and those participating only in track events on both days. 
Table 4 A comparison of energy expenditure between track and field events and track events during the preliminary competitions (the first day).

\begin{tabular}{|c|c|c|c|c|c|c|c|c|}
\hline Day 1 & & & $n$ & $M$ & SD & $Z$ & $P$ & $d$ \\
\hline \multirow{8}{*}{$\begin{array}{l}\text { Sample } \\
(n=75)\end{array}$} & \multirow{2}{*}{ RAEE/h } & $\mathrm{TF}$ & 32 & 0.86 & 0.25 & \multirow{2}{*}{1.20} & \multirow{2}{*}{0.23} & \multirow{2}{*}{0.29} \\
\hline & & $\mathrm{T}$ & 37 & 0.80 & 0.28 & & & \\
\hline & \multirow{2}{*}{ RTEE/h } & $\mathrm{TF}$ & 32 & 1.97 & 0.22 & \multirow{2}{*}{1.68} & \multirow{2}{*}{0.09} & \multirow{2}{*}{0.40} \\
\hline & & $\mathrm{T}$ & 37 & 1.88 & 0.26 & & & \\
\hline & \multirow{2}{*}{ TREE/h/24 } & $\mathrm{TF}$ & 32 & 1.58 & 0.15 & \multirow{2}{*}{1.16} & \multirow{2}{*}{0.25} & \multirow{2}{*}{0.28} \\
\hline & & $\mathrm{T}$ & 37 & 1.52 & 0.17 & & & \\
\hline & \multirow{2}{*}{ Steps } & $\mathrm{TF}$ & 32 & 16,344 & 4,176 & \multirow{2}{*}{0.74} & \multirow{2}{*}{0.46} & \multirow{2}{*}{0.18} \\
\hline & & $\mathrm{T}$ & 37 & 15,356 & 5,073 & & & \\
\hline \multirow{8}{*}{$\begin{array}{l}\text { Male } \\
(n=50)\end{array}$} & \multirow{2}{*}{$\mathrm{RAEE} / \mathrm{h}$} & $\mathrm{TF}$ & 18 & 0.88 & 0.22 & \multirow{2}{*}{0.32} & \multirow{2}{*}{0.74} & \multirow{2}{*}{0.09} \\
\hline & & $\mathrm{T}$ & 28 & 0.88 & 0.27 & & & \\
\hline & \multirow{2}{*}{ RTEE/h } & $\mathrm{TF}$ & 18 & 1.20 & 0.18 & \multirow{2}{*}{0.56} & \multirow{2}{*}{0.57} & \multirow{2}{*}{0.17} \\
\hline & & $\mathrm{T}$ & 28 & 1.96 & 0.24 & & & \\
\hline & \multirow{2}{*}{ TREE/h/24 } & $\mathrm{TF}$ & 18 & 1.60 & 0.13 & \multirow{2}{*}{0.21} & \multirow{2}{*}{0.83} & \multirow{2}{*}{0.06} \\
\hline & & $\mathrm{T}$ & 28 & 1.58 & 0.15 & & & \\
\hline & \multirow{2}{*}{ Steps } & $\mathrm{TF}$ & 18 & 15,258 & 4,233 & \multirow{2}{*}{1.29} & 020 & 038 \\
\hline & & $\mathrm{T}$ & 28 & 17,017 & 4,136 & & 0.20 & 0.38 \\
\hline & $\mathrm{R} \triangle \mathrm{FF} / \mathrm{h}$ & $\mathrm{TF}$ & 14 & 0.84 & 0.30 & 220 & $0 \Omega 2 *$ & 164 \\
\hline & КАЕЕ/ПI & $\mathrm{T}$ & 9 & 0.54 & 0.14 & 2.29 & 0.02 & 1.04 \\
\hline & RTFE/h & $\mathrm{TF}$ & 14 & 1.94 & 0.27 & 268 & $001 *$ & 191 \\
\hline Female $(n=$ & КILE/II & $\mathrm{T}$ & 9 & 1.65 & 0.17 & 2.00 & 0.01 & 1.01 \\
\hline & TREF/h/24 & $\mathrm{TF}$ & 14 & 1.55 & 0.12 & 236 & $\Omega \Omega 0 *$ & 160 \\
\hline & $1 \mathrm{KEE} / \mathrm{h} / 24$ & $\mathrm{~T}$ & 9 & 1.35 & 0.17 & 2.36 & $0.02^{*}$ & 1.69 \\
\hline & Stens & $\mathrm{TF}$ & 14 & 17,739 & 3,797 & 305 & $<0 \Omega 1 *$ & 218 \\
\hline & Stcps & $\mathrm{T}$ & 9 & 10,189 & 4,285 & 5.00 & -0.01 & 2.10 \\
\hline
\end{tabular}

$\mathrm{TF}=$ track and field events; $\mathrm{T}$ = track events; RAEE/h = relative active energy expenditure per hour; RTEE/h = total relative energy expenditure per hour for the time of measurement; TREE/h/24 = total relative energy expenditure per hour per 24 hours; $n=$ number of participants; $M=$ mean; $\mathrm{SD}=$ standard deviation; $Z=\mathrm{Z}$-score of Mann-Whitney $\mathrm{U}$ test; $P=$ statistical significance; $d=$ effect size coefficient. $* P<0.05$.

To be more precise, it was selected the period of time when athletes were participating in sports activity, according to the data from the SONAC over the 2 days. The AORP (average overall relative performances) is presented in METs, and the steps related to sports activities during these two days are presented as well (Table 6). It is shown that the track and field athletes have higher PA intensity and took more steps during the sports activities.

\subsection{The Comparison of PA Levels between High-Level} Events and Low-Level Events

While comparing the time for vigorous/moderate/light/sedentary activity between high-level athletic events and low-level events, it was obvious that the athletes who participated in high-level events spent more time taking part in vigorous activity during both the preliminary and final days. This means that athletes with a higher sporting ability have a higher PA level than those with a lower sporting ability (Tables 7 and 8). No statistical significance was found when comparing male-female findings.

\section{Discussion}

The main aim of this study was to measure PA using an accelerometer in athletes with a mental disability during a Special Olympic National Athletic Competition, and to analyze the level of PA in relation to different events and the gender of the participants. 
Table 5 A comparison of energy expenditure between track and field events and track events during the final competitions (the second day).

\begin{tabular}{|c|c|c|c|c|c|c|c|c|}
\hline Day 2 & & & $n$ & $M$ & SD & $Z$ & $P$ & $d$ \\
\hline \multirow{8}{*}{$\begin{array}{l}\text { Sample } \\
(n=75)\end{array}$} & \multirow{2}{*}{ RAEE/h } & $\mathrm{TF}$ & 32 & 0.58 & 0.21 & \multirow{2}{*}{1.58} & \multirow{2}{*}{0.11} & \multirow{2}{*}{0.38} \\
\hline & & $\mathrm{T}$ & 37 & 0.66 & 0.25 & & & \\
\hline & \multirow{2}{*}{ RTEE/h } & $\mathrm{TF}$ & 32 & 1.69 & 0.18 & \multirow{2}{*}{1.20} & \multirow{2}{*}{0.23} & \multirow{2}{*}{0.29} \\
\hline & & $\mathrm{T}$ & 37 & 1.75 & 0.25 & & & \\
\hline & \multirow{2}{*}{ TREE/h/24 } & $\mathrm{TF}$ & 32 & 1.46 & 0.14 & \multirow{2}{*}{1.13} & \multirow{2}{*}{0.26} & \multirow{2}{*}{0.27} \\
\hline & & $\mathrm{T}$ & 37 & 1.50 & 0.17 & & & \\
\hline & \multirow{2}{*}{ Steps } & $\mathrm{TF}$ & 32 & 11,563 & 3,630 & \multirow{2}{*}{3.18} & \multirow{2}{*}{$0.00 *$} & \multirow{2}{*}{0.77} \\
\hline & & $\mathrm{T}$ & 37 & 14,547 & 4,664 & & & \\
\hline \multirow{8}{*}{$\begin{array}{l}\text { Male } \\
(n=50)\end{array}$} & \multirow{2}{*}{ RAEE/h } & $\mathrm{TF}$ & 18 & 0.60 & 0.19 & \multirow{2}{*}{1.64} & \multirow{2}{*}{0.10} & \multirow{2}{*}{0.48} \\
\hline & & $\mathrm{T}$ & 28 & 0.70 & 0.25 & & & \\
\hline & \multirow{2}{*}{ RTEE/h } & $\mathrm{TF}$ & 18 & 1.71 & 0.18 & \multirow{2}{*}{0.96} & \multirow{2}{*}{0.34} & \multirow{2}{*}{0.28} \\
\hline & & $\mathrm{T}$ & 28 & 1.78 & 0.26 & & & \\
\hline & \multirow{2}{*}{ TREE/h/24 } & $\mathrm{TF}$ & 18 & 1.48 & 0.15 & \multirow{2}{*}{0.74} & \multirow{2}{*}{0.46} & \multirow{2}{*}{0.22} \\
\hline & & $\mathrm{T}$ & 28 & 1.51 & 0.18 & & & \\
\hline & \multirow{2}{*}{ Steps } & $\mathrm{TF}$ & 18 & 11,418 & 3,130 & \multirow{2}{*}{2.94} & $000 *$ & 087 \\
\hline & & $\mathrm{T}$ & 28 & 14,828 & 4,359 & & $0.00^{2}$ & 0.81 \\
\hline & $\mathrm{P} \triangle \mathrm{FE} / \mathrm{h}$ & $\mathrm{TF}$ & 14 & 0.56 & 0.24 & $0 \Omega 0$ & 100 & 0 \\
\hline & КละЕ/ก & $\mathrm{T}$ & 9 & 0.57 & 0.27 & 0.00 & 1.00 & 0 \\
\hline & RTEF/h & $\mathrm{TF}$ & 14 & 1.66 & 0.18 & 000 & 100 & 0 \\
\hline Female & КILE/II & $\mathrm{T}$ & 9 & 1.67 & 0.24 & & 1.00 & 0 \\
\hline & TPEF/h/24 & $\mathrm{TF}$ & 14 & 1.44 & 0.14 & 038 & 070 & ק 07 \\
\hline & $1 \mathrm{KEE} / \mathrm{h} / 24$ & $\mathrm{~T}$ & 9 & 1.46 & 0.16 & 0.38 & 0.10 & 0.21 \\
\hline & Stens & $\mathrm{TF}$ & 14 & 11,749 & 4,307 & 129 & 020 & 092 \\
\hline & Stcps & $\mathrm{T}$ & 9 & 13,671 & 5,711 & 1.29 & 0.20 & 0.92 \\
\hline
\end{tabular}

$\mathrm{TF}=$ track and field events; $\mathrm{T}$ = track events; RAEE/h = relative active energy expenditure per hour; RTEE/h = total relative energy expenditure per hour for the time of measurement; TREE/h/24 = total relative energy expenditure per hour per 24 hours; $n=$ number of participants; $M=$ mean; $\mathrm{SD}=$ standard deviation; $Z=\mathrm{Z}$-score of Mann-Whitney U test; $P=$ statistical significance; $d=$ effect size coefficient. $* P<0.05$.

Table 6 The average overall relative performances and steps during the sports activities during the SONAC-2 days.

\begin{tabular}{|c|c|c|c|c|c|c|c|c|}
\hline Workout & & & $n$ & $M$ & SD & $Z$ & $P$ & $d$ \\
\hline \multirow{4}{*}{ Sample } & \multirow{2}{*}{ AORP (METs) } & $\mathrm{TF}$ & 27 & 1.55 & 0.36 & \multirow{2}{*}{2.03} & \multirow{2}{*}{$0.04 *$} & \multirow{2}{*}{0.58} \\
\hline & & $\mathrm{T}$ & 21 & 1.32 & 0.35 & & & \\
\hline & \multirow{2}{*}{ Steps } & $\mathrm{TF}$ & 27 & 5,114 & 2,339 & \multirow{2}{*}{3.43} & \multirow{2}{*}{$0.00 *$} & \multirow{2}{*}{0.99} \\
\hline & & $\mathrm{T}$ & 21 & 2,566 & 2,142 & & & \\
\hline \multirow{4}{*}{ Male } & \multirow{2}{*}{ AORP (METs) } & $\mathrm{TF}$ & 17 & 1.45 & 0.37 & \multirow{2}{*}{1.24} & \multirow{2}{*}{0.21} & \multirow{2}{*}{0.43} \\
\hline & & $\mathrm{T}$ & 16 & 1.30 & 0.39 & & & \\
\hline & \multirow{2}{*}{ Steps } & $\mathrm{TF}$ & 17 & 5,023 & 2,104 & \multirow{2}{*}{2.58} & \multirow{2}{*}{$0.01 *$} & \multirow{2}{*}{0.90} \\
\hline & & $\mathrm{T}$ & 16 & 2,708 & 2,266 & & & \\
\hline \multirow{4}{*}{ Female } & \multirow{2}{*}{ AORP (METs) } & $\mathrm{TF}$ & 10 & 1.71 & 0.28 & \multirow{2}{*}{1.90} & \multirow{2}{*}{0.06} & \multirow{2}{*}{0.98} \\
\hline & & $\mathrm{T}$ & 5 & 1.39 & 0.20 & & & \\
\hline & \multirow{2}{*}{ Steps } & $\mathrm{TF}$ & 10 & 5,268 & 2,809 & \multirow{2}{*}{2.02} & \multirow{2}{*}{$0.04 *$} & \multirow{2}{*}{1.04} \\
\hline & & $\mathrm{T}$ & 5 & 2,112 & 1,830 & & & \\
\hline
\end{tabular}

$\mathrm{TF}=$ track and field events; $\mathrm{T}=$ track events; AORP $=$ the average overall relative performances; $n=$ number of participants; $M=$ mean; $\mathrm{SD}=$ standard deviation; $Z=\mathrm{Z}$-score of Mann-Whitney U test; $P=$ statistical significance; $d=$ effect size coefficient. $* P<$ 0.05 . 
Table 7 The comparison of PA levels between high-level athletic events and low-level events during the preliminary day.

\begin{tabular}{|c|c|c|c|c|c|c|c|c|}
\hline Day 1 & & & $n$ & $M$ & SD & $Z$ & $P$ & $d$ \\
\hline \multirow{6}{*}{$\begin{array}{l}\text { Vigorous } \\
\text { (min) }\end{array}$} & \multirow{2}{*}{$\begin{array}{l}\text { Sample } \\
(n=75)\end{array}$} & $\mathrm{L}$ & 21 & 1.95 & 3.38 & \multirow{2}{*}{2.22} & \multirow{2}{*}{$0.03 *$} & \multirow{2}{*}{0.51} \\
\hline & & $\mathrm{H}$ & 54 & 7.04 & 11.84 & & & \\
\hline & Male & $\mathrm{L}$ & 7 & 3.14 & 3.93 & \multirow{2}{*}{0.83} & \multirow{2}{*}{0.40} & \multirow{2}{*}{0.23} \\
\hline & $(n=50)$ & $\mathrm{H}$ & 43 & 8.30 & 12.93 & & & \\
\hline & \multirow{2}{*}{$\begin{array}{l}\text { Female } \\
(n=25)\end{array}$} & $\mathrm{L}$ & 14 & 1.36 & 3.05 & \multirow{2}{*}{1.17} & \multirow{2}{*}{0.24} & \multirow{2}{*}{0.47} \\
\hline & & $\mathrm{H}$ & 11 & 2.09 & 2.66 & & & \\
\hline \multirow{6}{*}{$\begin{array}{l}\text { Moderate } \\
(\mathrm{min})\end{array}$} & \multirow{2}{*}{$\begin{array}{l}\text { Sample } \\
(n=75)\end{array}$} & $\mathrm{L}$ & 21 & 72.67 & 45.73 & \multirow{2}{*}{0.58} & \multirow{2}{*}{0.56} & \multirow{2}{*}{0.13} \\
\hline & & $\mathrm{H}$ & 54 & 78.54 & 43.45 & & & \\
\hline & \multirow{2}{*}{$\begin{array}{l}\text { Male } \\
(n=50)\end{array}$} & $\mathrm{L}$ & 7 & 93.00 & 32.22 & \multirow{2}{*}{0.12} & \multirow{2}{*}{0.89} & \multirow{2}{*}{0.03} \\
\hline & & $\mathrm{H}$ & 43 & 86.35 & 40.81 & & & \\
\hline & \multirow{2}{*}{$\begin{array}{l}\text { Female } \\
(n=25)\end{array}$} & $\mathrm{L}$ & 14 & 62.50 & 49.03 & \multirow{2}{*}{0.46} & \multirow{2}{*}{0.64} & \multirow{2}{*}{0.18} \\
\hline & & $\mathrm{H}$ & 11 & 48.00 & $41, .52$ & & & \\
\hline \multirow{6}{*}{$\begin{array}{l}\text { Light } \\
(\min )\end{array}$} & \multirow{2}{*}{$\begin{array}{l}\text { Sample } \\
(n=75)\end{array}$} & $\mathrm{L}$ & 21 & 104.24 & 33.79 & \multirow{2}{*}{0.36} & \multirow{2}{*}{0.72} & \multirow{2}{*}{0.08} \\
\hline & & $\mathrm{H}$ & 54 & 113.63 & 55.90 & & & \\
\hline & \multirow{2}{*}{$\begin{array}{l}\text { Male } \\
(n=50)\end{array}$} & $\mathrm{L}$ & 7 & 102.86 & 18.87 & \multirow{2}{*}{0.22} & 082 & 006 \\
\hline & & $\mathrm{H}$ & 43 & 110.86 & 58.51 & & 0.02 & 0.00 \\
\hline & Female & $\mathrm{L}$ & 14 & 104.93 & 39.89 & 126 & 09 & 50 \\
\hline & $(n=25)$ & $\mathrm{H}$ & 11 & 124.45 & 44.99 & 1.20 & 0.21 & 0.50 \\
\hline & Sample & $\mathrm{L}$ & 21 & 287.05 & 86.31 & 274 & & \\
\hline & $(n=75)$ & $\mathrm{H}$ & 54 & 350.33 & 89.34 & 2.14 & $0.01 \%$ & 0.03 \\
\hline Sedentary & Male & $\mathrm{L}$ & 7 & 292.71 & 86.00 & 183 & 006 & 052 \\
\hline$(\min )$ & $(n=50)$ & $\mathrm{H}$ & 43 & 357.53 & 93.49 & 1.83 & 0.00 & 0.52 \\
\hline & Female & $\mathrm{L}$ & 14 & 284.21 & 89.56 & 1.12 & 0.26 & 0.45 \\
\hline & $(n=25)$ & $\mathrm{H}$ & 11 & 322.18 & 67.04 & & & $0.4 J$ \\
\hline
\end{tabular}

$\mathrm{H}=$ high-level sports athletes; $\mathrm{L}=$ low-level sports athletes; $n=$ number of participants; $M=$ mean; $\mathrm{SD}=$ standard deviation; $\mathrm{Z}=$ Z-score of Mann-Whitney U test; $P=$ statistical significance; $d=$ effect size coefficient. $* P<0.05$.

From previous studies, Temple et al. [23] indicated that less than one-third of adults with an intellectual disability are sufficiently PA to meet health promotion guidelines for PA, and Shield et al. [26] found that only $42.1 \%$ of children completed at least 60 minutes of MVPA (moderate to vigorous physical activity) each day. However, it was found that during the two days of the SONAC, the average time the athletes spent taking part in MVPA was over 60 minutes, and the total steps taken exceeded the guideline of 10,000 steps per day as well, which is relevant to the general recommendation [24, 28]. Besides the amount of steps the athletes took, they stayed active for $60 \%$ of the day. All the evidence above indicates that the Special Olympic program, as a well-planned exercise program, can help people with a mental disability live an active lifestyle, which is in line with the findings from
Johnson [21], who states that children and adolescents with mental disabilities derive health benefits from participation in group exercise programs. It is necessary to take in account that the positive results were completed during the Special Olympics competition. Similar activity should be achievable everyday with Special Olympics training. Válková [8] wrote that 53 minutes of PA per day is possible to achieve with trained educators-coaches.

As we know, aerobic exercises and anaerobic exercises have different effects on the human body. Therefore, we grouped Special Olympic athletes into a track events group (aerobic exercise domain) and a track and field events group (both aerobic and anaerobic exercise domain) to see if any differences exist between these two groups. It is interesting to note that on the preliminary day, the female track and 
Table 8 A comparison of PA levels between high-level athletic events and low-level events during the final day.

\begin{tabular}{|c|c|c|c|c|c|c|c|c|}
\hline Day 2 & & & $n$ & $M$ & SD & $Z$ & $P$ & $d$ \\
\hline \multirow{6}{*}{$\begin{array}{l}\text { Vigorous } \\
\text { (min) }\end{array}$} & \multirow{2}{*}{$\begin{array}{l}\text { Sample } \\
(n=75)\end{array}$} & $\mathrm{L}$ & 21 & 1.33 & 2.67 & \multirow{2}{*}{2.88} & \multirow{2}{*}{$0.00 *$} & \multirow{2}{*}{0.67} \\
\hline & & $\mathrm{H}$ & 54 & 5.63 & 10.23 & & & \\
\hline & Male & $\mathrm{L}$ & 7 & 0.86 & 0.90 & \multirow{2}{*}{1.72} & \multirow{2}{*}{0.08} & \multirow{2}{*}{0.49} \\
\hline & $(n=50)$ & $\mathrm{H}$ & 43 & 6.65 & 11.25 & & & \\
\hline & \multirow{2}{*}{$\begin{array}{l}\text { Female } \\
(n=25)\end{array}$} & $\mathrm{L}$ & 14 & 1.57 & 3.34 & \multirow{2}{*}{2.10} & \multirow{2}{*}{$0.03 *$} & \multirow{2}{*}{0.84} \\
\hline & & $\mathrm{H}$ & 11 & 1.64 & 0.92 & & & \\
\hline \multirow{6}{*}{$\begin{array}{l}\text { Moderate } \\
(\mathrm{min})\end{array}$} & \multirow{2}{*}{$\begin{array}{l}\text { Sample } \\
(n=75)\end{array}$} & $\mathrm{L}$ & 21 & 51.38 & 37.71 & \multirow{2}{*}{1.12} & \multirow{2}{*}{0.26} & \multirow{2}{*}{0.25} \\
\hline & & $\mathrm{H}$ & 54 & 61.04 & 36.08 & & & \\
\hline & \multirow{2}{*}{$\begin{array}{l}\text { Male } \\
(n=50)\end{array}$} & $\mathrm{L}$ & 7 & 48.14 & 20.48 & \multirow{2}{*}{1.59} & \multirow{2}{*}{0.11} & \multirow{2}{*}{0.45} \\
\hline & & $\mathrm{H}$ & 43 & 66.23 & 36.57 & & & \\
\hline & \multirow{2}{*}{$\begin{array}{l}\text { Female } \\
(n=25)\end{array}$} & $\mathrm{L}$ & 14 & 53.00 & 44.56 & \multirow{2}{*}{0.44} & \multirow{2}{*}{0.66} & \multirow{2}{*}{0.18} \\
\hline & & $\mathrm{H}$ & 11 & 40.73 & 26.68 & & & \\
\hline \multirow{6}{*}{$\begin{array}{l}\text { Light } \\
(\min )\end{array}$} & \multirow{2}{*}{$\begin{array}{l}\text { Sample } \\
(n=75)\end{array}$} & $\mathrm{L}$ & 21 & 98.00 & 49.90 & \multirow{2}{*}{0.80} & \multirow{2}{*}{0.42} & \multirow{2}{*}{0.18} \\
\hline & & $\mathrm{H}$ & 54 & 106.98 & 57.57 & & & \\
\hline & \multirow{2}{*}{$\begin{array}{l}\text { Male } \\
(n=50)\end{array}$} & $\mathrm{L}$ & 7 & 81.14 & 40.23 & \multirow{2}{*}{1.18} & 0.23 & 033 \\
\hline & & $\mathrm{H}$ & 43 & 105.14 & 59.56 & & 0.23 & 0.33 \\
\hline & Female & $\mathrm{L}$ & 14 & 106.43 & 53.43 & 047 & 064 & 019 \\
\hline & $(n=25)$ & $\mathrm{H}$ & 11 & 114.18 & 50.91 & 0.41 & 0.04 & 0.19 \\
\hline & Sample & $\mathrm{L}$ & 21 & 333.67 & 100.45 & 162 & 0 & 037 \\
\hline & $(n=75)$ & $\mathrm{H}$ & 54 & 382.06 & 94.03 & 1.02 & 0.10 & 0.31 \\
\hline Sedentary & Male & $\mathrm{L}$ & 7 & 347.57 & 130.64 & 071 & 0.49 & 020 \\
\hline$(\min )$ & $(n=50)$ & $\mathrm{H}$ & 43 & 388.93 & 96.03 & 0.71 & 0.49 & 0.20 \\
\hline & Female & $\mathrm{L}$ & 14 & 326.71 & 86.55 & 0.68 & 0.49 & 0.27 \\
\hline & $(n=25)$ & $\mathrm{H}$ & 11 & 355.18 & 84.46 & & & \\
\hline
\end{tabular}

$\mathrm{H}=$ high-level sports athletes; $\mathrm{L}=$ low-level sports athletes; $n=$ number of participants; $M=$ mean; $\mathrm{SD}=$ standard deviation; $Z=$ Z-score of Mann-Whitney U test; $P=$ statistical significance; $d=$ effect size coefficient. $* P<0.05$.

field group had higher energy expenditure than the track group, but on the final day the results were the reverse, with the track group taking more steps than the track and field group.

In order to be more precise, the period of time when athletes were participating in sports activity over the two days of the SONAC was selected. The average overall relative performances and steps from the track and field athletes were significantly higher during sports activities. We can anticipate warming time before competition and then competition in track or field events.

In the Special Olympics, every effort is made to place athletes in divisions where their performance ability is no more than $15 \%$ higher or lower than others in the same division [7], which means that the Special Olympic athletes are grouped by their sporting ability. The difference in PA between athletes who participate in high-level sports and those who participate in low-level sports is shown by the amount of time spent taking part in vigorous activity. Athletes with a higher sporting ability tend to spend more time participating in vigorous activity. It is therefore possible to justify the regulation of having lower and higher ability events, relevant to athletes' abilities, which are linked to their mental level, achieved skills and the safety process. Coaches are educated to apply this regulation.

\section{Study Limitations}

The study was undertaken during the SONAC in the Czech Republic. The number of athletes from each group was small, just 50 male and 25 female athletes. The data is relevant only to special competitive 
situations. The energy expenditure and PA levels of these athletes during their daily life is not sufficient. Nevertheless, the presented idea is the first to use an accelerometer to compare PA during a SONAC.

\section{Conclusion}

The purpose of the presented research project was to provide information about PA of Special Olympic athletes during a two-day athletics (track and field) competition.

Athletes, both male and female, were physically active for around $60 \%$ of the day. Similar results were found on both days: during the preliminary competition and during the final competition. The amount of steps per day is in keeping with the general recommendation $(10,000)$. It means athletes met the recommended PA level, and they were relatively active during the SONAC. No significant differences were found in active energy expenditure between athletes participating in track and field events and those participating only in track events on both days. Athletes who participated in high-level events spent more time taking part in vigorous activity during both the preliminary and final competitions, which means athletes with a higher sporting ability have a higher PA level than those with a lower sporting ability. In spite of the visual differences between the male-female findings, no statistically significant differences were confirmed. The inclusion in athletic events (lower level event) is more strongly linked to an athlete's mental level rather than gender or preliminary and/or final day of competition. Even though the research study is limited to 50 male and 25 female athletes and two days of Special Olympic competition, the results can lead to continuous research and further optimize the development of PA programs for people with a mental disability.

\section{References}

[1] Murphy, S. L. 2009. "Review of Physical Activity Measurement Using Accelerometers in Older Adults:
Considerations for Research Design and Conduct." Preventive Medicine 48 (2): 108-14.

[2] U.S. Department of Health and Human Services. 2009. "Healthy People 2020." Accessed May 15, 2014. http://www.healthypeople.gov/hp2020/Objectives/files/D raft2009Objectives.pdf.

[3] World Health Organization. 2009. "Health and Development through Physical Activity and Sport." Accessed May 15, 2014. http://whqlibdoc.who.int/hq/2003/WHO_NMH_NPH_PA H_03.2.pdf

[4] U.S. Department of Health and Human Services. 2002. "Physical Activity Guidelines for Americans, Be Active, Healthy, and Happy!" Accessed July 9, 2009. http://www.health.gov/paguidelines.

[5] Longmuir, P. E. and Bar-Or, O. 2000. "Factors Influencing the Physical Activity Levels of Youths with Physical and Sensory Disabilities." Adapted Physical Activity Quarterly 17 (1): 40-53.

[6] Sherrill, C. 2003. Adapted Physical Activity, Recreation and Sport. Crossdisciplinary and Lifespan. United States: McGraw-Hill Companies, Inc., 178-80.

[7] Special Olympics, Inc. 2002. "Ready Set Go Local Program Guide." Accessed November 17, 2004. http://www.specialolympics.org/uploadedFiles/local_pro gram_development_guide.pdf

[8] Válková, H. 2007. "Male-Female Residents with Mental Disability and Their Participation in Leisure Time of Physical Activities." In Sport \& Science, Supplement to Issue 2. CEEPUS, Adapted of Physical ActivitiesEuropean Dimensions, edited by Tzareva R. Sofia: Publishing House "Tip-Top Press", 13-7.

[9] Cratty, B. 1972. The Special Olympics: A National Opinion Survey. United States, UCLA.

[10] Barnhart, R. C., and Connolly, B. 2007. "Aging and Down Syndrome: Implications for Physical Therapy." Physical Therapy 87 (10): 1399-406.

[11] Draheim, C. C. 2006. "Cardiovascular Disease Prevalence and Risk Factors of Persons with Mental Retardation." Mental Retardation and Developmental Disabilities Research Reviews 12 (1): 3-12.

[12] Draheim, C. C., Williams, D. P., and McCubbin, J. A. 2002. "Prevalence of Physical Inactivity and Recommended Physical Activity in Community-Based Adults with Mental Retardation". Mental Retardation 40 (6): 436-44.

[13] Dykens, E. M., and Cohen, D. J. 1996. "Effects of Special Olympics International on Social Competence in Persons with Mental Retardation." Journal of the American Academy of Child \& Adolescent Psychiatry 35 (2): 223-9. 
[14] Wright, J., and Cowden, J. E. 1986. "Research Changes in Self-concept and Cardiovascular Endurance of Mentally Retarded Youths in a Special Olympics Swim Training Program." Adapted Physical Activity Quarterly 3 (2): 177-83.

[15] Fernhall, B., Pitetti, K. H., Rimmer, J. H., Mccubbin, J. A., Rintala, P., Millar, A. L., Kittredge, J., and Burkett, L. N. 1996. "Cardiorespiratory Capacity of Individuals with Mental Retardation including Down Syndrome." Medicine and Science in Sports and Exercise 28 (3): 366-71.

[16] Onywadume, I. 2008. "Physical Activity, Physical Fitness and Obesity of Special Olympians in Nigeria." In Proceedings of EUCAPA Conference 2008 in Torino, edited by Bianco, A. Torino: University in Torino, 67.

[17] Robertson, J., Emerson, E., Gregory, N., Hatton, C., Turner, S., Kessissoglou, S., and Hallam, A. 2000. "Lifestyle Related Risk Factors for Poor Health in Residential Settings for People with Intellectual Disabilities." Research in Developmental Disabilities 21 (6): 469-86.

[18] Yamaki, K. 2005. "Body Weight Status among Adults with Intellectual Disability in the Community."Mental Retardation 43 (1): 1-10.

[19] Foley, J. Z., Bryan, R. R. and Mccubbin, J. A. 2008. "Daily Physical Activity Levels of ELementary School-Aged Children with and without Mental Retardation." Journal of Developmental and Physical Disabilities 20 (4): 365-78.

[20] Frey, G. C., Stanish, H. I., and Temple, V. A. 2008. "Physical Activity of Youth with Intellectual Disability: Review and Research Agenda." Adapted Physical Activity Quarterly 25 (2): 95-117.

[21] Johnson, C. C. 2009. "The Benefits of Physical Activity for Youth with Developmental Disabilities: A Systematic Review." American Journal of Health Promotion 23 (3): 157-67.

[22] Peterson, J. J., Janz, K. F. and Lowe, J. B. 2008. "Physical Activity among Adults with Intellectual Disabilities Living in Community Settings." Preventive
Medicine 47 (1): 101-6.

[23] Temple, V. A., Frey, G. C. and Stanish, H. I. 2006. "Physical Activity of Adults with Mental Retardation: Review and Research Needs." American Journal of Health Promotion 21 (1): 2-12.

[24] Tudor-Locke, C., and Bassett Jr., D. R. 2004. "How Many Steps/Day Are Enough? Preliminary Pedometer Indices for Public Health.” Sports Medicine 34 (1): 1-8.

[25] Stanish, H. L., Temple, V. A. and Frey, G. C. 2006. "Health-Promoting Physical Activity of Adults with Mental Retardation." Mental Retardation and Developmental Disabilities Research Reviews 12 (1): 13-21.

[26] Shields, N., Dodd, K. J., and Abblitt, C. 2009. "Do Children with Down Syndrome Perform Sufficient Physical Activity to Maintain Good Health? A Pilot Study." Adapted Physical Activity Quarterly 26 (4): 307-20.

[27] Pitteti, K. H., Jackson, J. A., Stubbs, N. B., Campbell, K. D., and Battar, S. S. 1989. "Fitness Level of Adult Special Olympics participants." Adapted Physical Activity Quarterly 6 (4): 354-70.

[28] Pitteti, K. H. 2010. "Keynote Presentation in Gavle." In Book of EUCAPA Abstracts: APA over Life-Span European $A P A$, edited by Piispanen, T. Jyväskylä: University of Jyväskylä.

[29] Company Press Support. 2010. ActiGtraph Device-Life User Manual Rev. B. Accessed May 22, 2010. http://www.theactigraph.com/index.php?option=com_doc man\&task=doc_download\&gid=192\&Itemid $=64$

[30] Valanou, E. M., Bamia, C., and Trichopoulou, A. 2006. "Methodology of Physical-Activity and Energy-Expenditure Assessment: A Review." J. Public Health 14 (2): 58-65.

[31] Special Olympics, Inc., 2010. "Athletics Rules, Special Olympics Summer Sports Rules 2010.” Accessed March 28 , 2011. http://media.specialolympics.org/soi/files/sports/athletics _rules_2010.pdf. 